\title{
Development and Environment in Urmia Lake of Iran
}

\author{
Mohammad Bagher Ghalibaf', Zahra Moussavi²
}

\begin{abstract}
Since the end of the Second World War, the development paradigm has become the dominant discourse in the world. During the more than 6 decades that the concept of development discourse has been dominant, many theoretical and practical developments have accompanied it. At first, attention was solely centered on economic development and nature was considered as a facilitator of economic growth. However, it was gradually recognized that development with this economic growth approach changes the natural systems of the planet and leads to numerous environmental hazards that can threaten the economic and political systems of countries. Therefore, it is very possible for a political entity to attain development, but sustained development will be faced with serious doubts because environmental aspects are ignored. Therefore, the concept of sustainable development replaced development.

Given the above- mentioned approach, this descriptive-analytic research studied the relationship between economic development and the environment, with Urmia Lake as a case example. Findings of the research show that implementation of Development Plans has been one of the main reasons for the drying up of the Lake.
\end{abstract}

Key Words: Sustainable Development, Environment, Urmia Lake.

\section{Introduction}

Before the end of the Second World War, there was little worry about inequality among people of the world. With decolonization, and with the emergence of independent nation-states after the Second World War, inequality, poverty, and standard of living turned into worries for world political leaders (Warf, 2006, 10). With the proclamation of the Truman Doctrine in 1949, the world entered a new management era: development the main constituents of which were capital, sciences, and technology (Escobar, 1995, 3) and, thus, the first development theories appeared in the 1950s, after the Second World War placing the concept of development in the context of the Cold War, Arturo Escobar believes the emergence of development theories were more than a human ideal for expanding peace and justice in the world. He says this concept must be understood in relation to competition between the United States and the Soviet Union for attaining ideological and political supremacy in the world (Warf, 2006, 10).

\section{Economic growth and development}

In any case, the modern concept of development was adopted by the Third World as a way of attaining the historical experience of the First World that they needed

2 - PhD Candidate in Political Geography, University of Tehran. 
to achieve development. Therefore, in the beginning, development was synonymous with national economic growth and was considered the route to achieving those economic developments. Given the purely economic goal of development, economists were entrusted with planning for it and nature was considered as the required source of wealth.

Gradually, this traditional approach to development that was mainly rooted in classical and neoclassical economics (Potter \& Conway, 2011, 599) led to the emergence of many environmental problems in the world and to changes in the natural systems of the planet that could threaten the economic and political systems of countries.

\section{Sustainable Development}

With the emergence of social-environmental and economic failures, and with criticism being leveled at the one-dimensional understanding of development that considered it synonymous with economic growth, protests started to take place from the late 1960s, the culmination of which was the United Nations Conference for the Human Environment that was held in Stockholm in 1972 (Sarrafi, 1998, 37). Following that, numerous conferences were convened.

However, since developing countries were not optimistic about the declarations of these conferences and worried that restrictions could pose an obstacle in the path of Third World development and turn the inequalities between them and the developed countries into a permanent feature, the term "sustainable development" was coined for establishing a balance between development and preservation of the environment (Leftwich, 2006, 95). According to the famous Brundtland Report of 1987 concerning sustainable development published by the World Commission on Environment and Development, sustainable development is development that satisfies the present needs of man without reducing the ability of future generations in meeting their requirements (WCED, 1987). Therefore, as was later referred to in Agenda 21 too, the link between development and environment satisfies the basic needs of all human beings, and a more secure future will be waiting for coming generations (United Nations, 1992).

Nevertheless, and despite disturbances in nature have become apparent and people have generally accepted nature as an ecosystem they themselves are a part of, attempts are continuing to proceed with modern projects, although in these attempts nature is still viewed as "the other" and as a facilitator of economic strategies (Bordessa, 1993). However, visible environmental consequences have given us the insight that, although economic growth and instrumental rationality will very probably help a political entity to achieve development, non-optimal use of natural resources and disregard for the environmental aspects will put the continuation of this development into question. Therefore, this development cannot necessarily bring cultural, political, and social growth (Etaat et al., 2013, preface) and, hence, cannot be sustainable.

\section{Urmia Lake}

This lake, with an area of about 5000 square kilometers situated in Northeastern Iran, is the second largest salt lake in the world. This lake, together with its numerous islands, was declared a Protected Area in 1967 due to its unique characteristics and has been protected since 1970 as a National Park. In 1975, it was introduced as a Biosphere 
Reserve to UNESCO's program of Man and the Biosphere and was registered in that organization, and because it met the criteria of the Convention on Wetlands of International Importance (Ramsar-1971), it was included in the list of the Wetlands of this Convention (DOE, 2013a).

Fig1. General Location of Urmia Lake

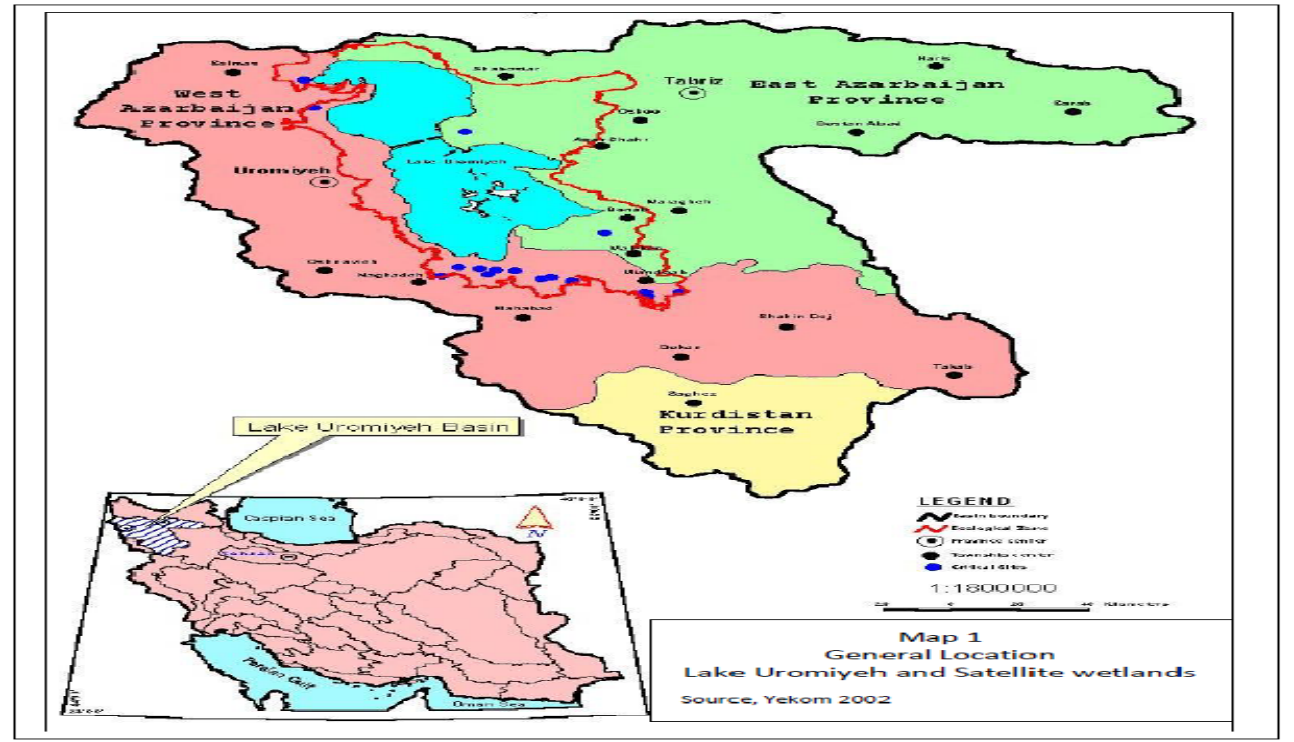

Source: Yekom Consuling Engineers, 2002.

The water level in Urmia Lake was at its highest in 1995. Since then, and up to 2011, we witnessed a sharp drop in the water level amounting to more than seven meters. This has greatly influenced the physiography, geomorphology, and hydrography of the Lake. The effects of the receding and advancing of the water in the Lake are greater on the eastern and southern shores compared to the other areas due to the low slope of these shores (Heydari, 2013).

Based on studies of the past two decades, as long as the water level of the Lake fluctuates at levels higher than 1274.1 meters above sea level, it will continue its normal ecological function for preserving its environmental diversity. Levels lower than 1274.1 meters above sea level will have negative effects on the ecological functions of the Lake (DOE, 2010, 18). This while, according to statistics published on the website of West Azarbaijan Regional Water Company, the water level of the Lake declined from 1275.74 meters in 1978 to 1270.91 meters in 2012 (West Azerbaijan Regional Water Authority Website). 
Fig2. Changes in Water Level of Urmia Lake

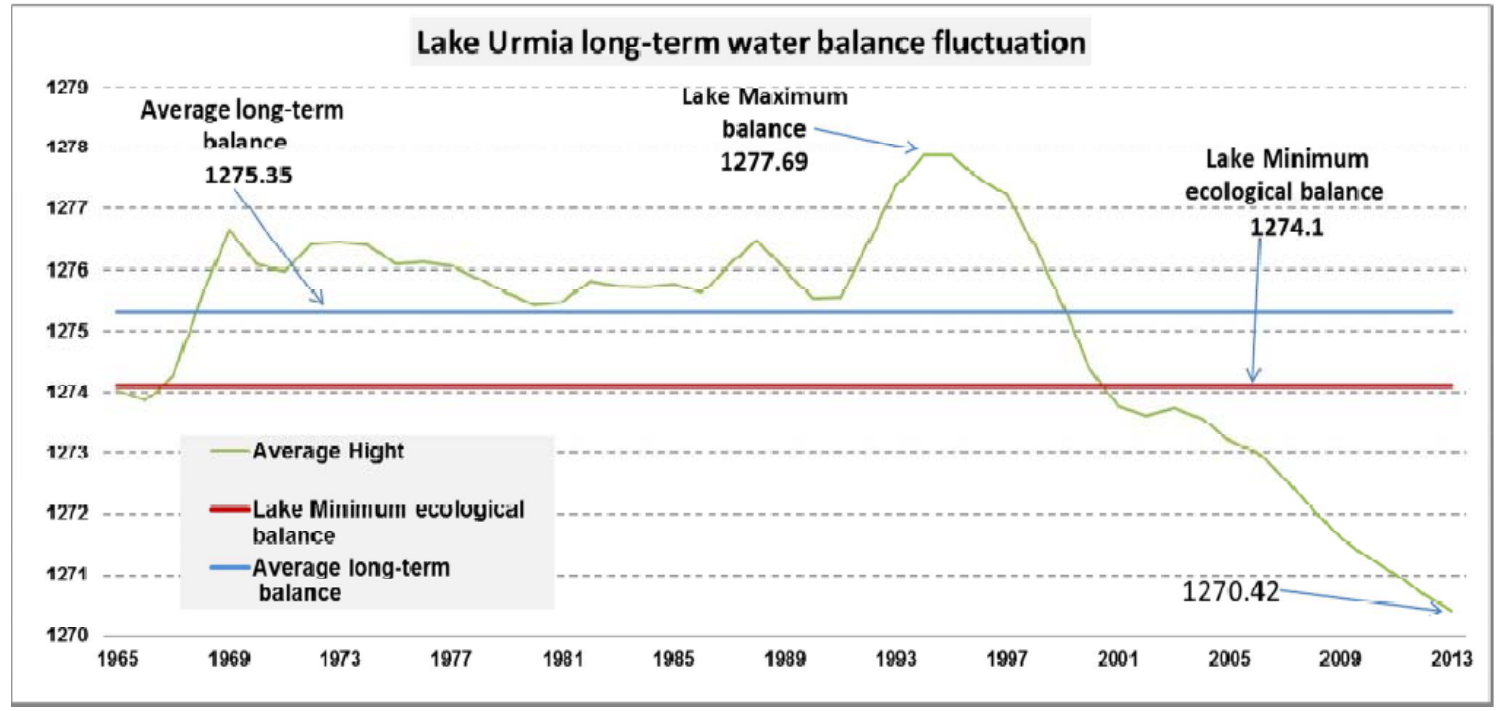

Source: DOE, $2013 a$.

Fig3. Satellite Images of Changes in Surface of Urmia Lake
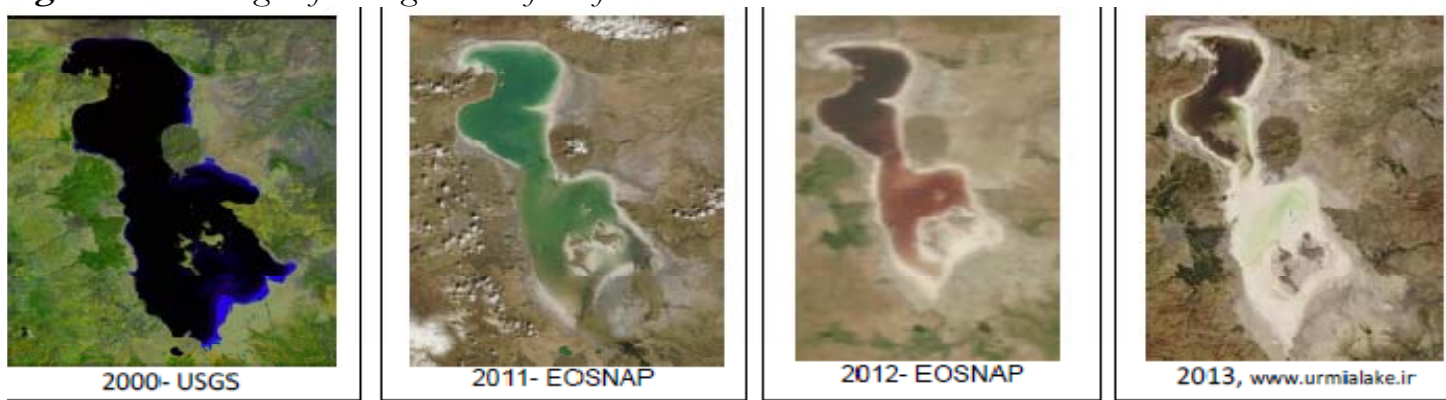

2013, www.urmialake.ir

Source: DOE, $2013 a$.

\section{4-A-Major Development Plans in Lake Orumiyeh Basin}

\section{i. Dam construction}

Based on studies by the Environmental Protection Organization, at present there are about 95 dams in the Urmia Lake Basin, 57 of which are operational, nine are being built, and 29 are in the study phase (DOE, 2013b).

\section{ii. Excessive use of groundwater}

In the Urmia Lake Basin, 59 percent of water used is obtained from surface water and 41 percent from groundwater sources. Well water utilization has increased very rapidly in the past two decades (87 percent for the agriculture sector and 13 percent as drinking water and water for industries) and has depleted more than 90 percent of the water in the aquifers. This has caused a continuous drop in the water level of some aquifers so that, based on available statistics, of the wells in the aquifers bordering the Lake that are in direct contact with it (9459 deep and semi-deep wells), the water in 1002 ( 10.6 percent) of the wells have turned salty leading to their 
abandonment. This shows the increase in utilization of groundwater (Iranian Community Consulting Engineers, 2011).

Fig4. Dams on Urmia Lake

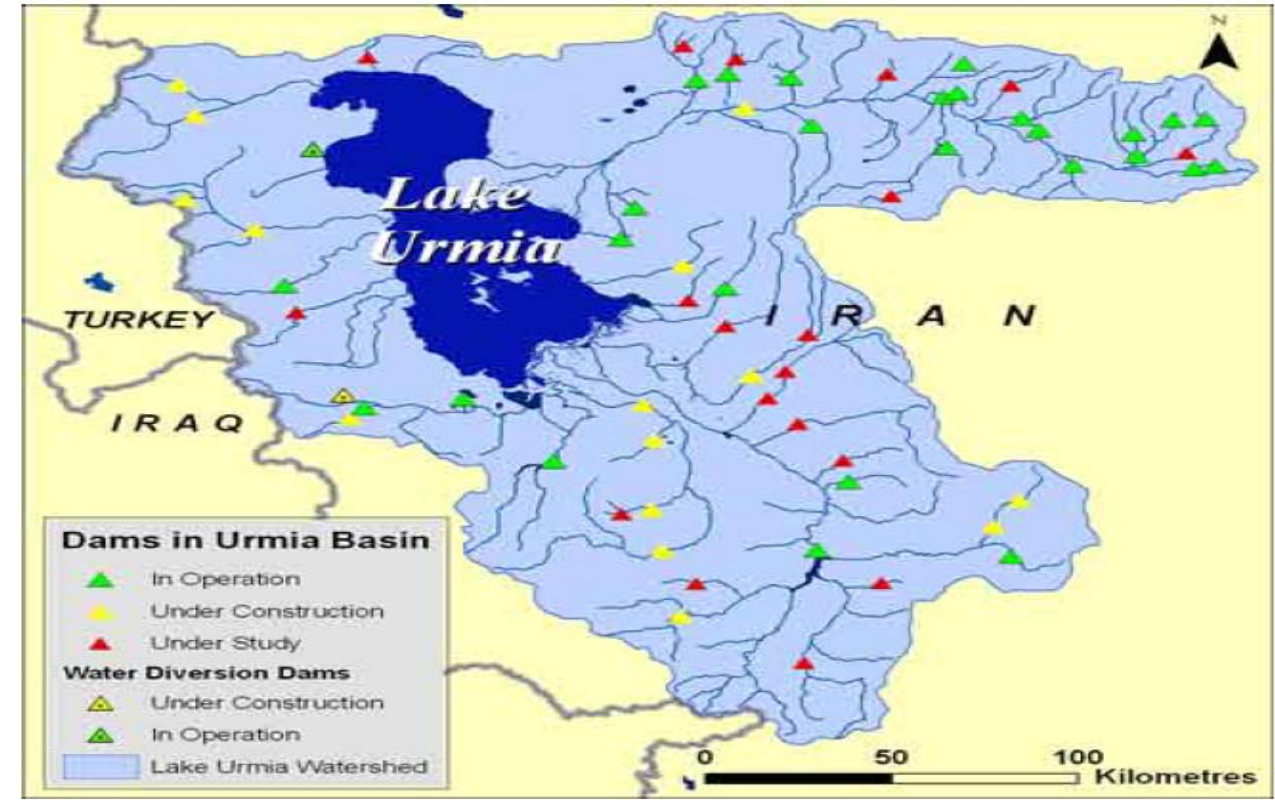

Source: UNEP, 2012.

\section{iii. Increase in agricultural activities and in water use}

Eighty-seven percent of the surface and underground water in the Urmia Lake Basin is devoted to the agriculture sector. In fact, the agriculture sector is the most important consumer of the water in this Basin and has experienced remarkable changes during the last three decades (Iranian Community Consulting Engineers, 2011).

\section{iv. The Shahid Kalantari Highway}

Another destructive factor of the Lake was the construction of a causeway the most part of which was built by constructing a levee in the Lake. The building of this causeway has had significant effects on the hydrological and hydrodynamic activities of the Lake and on the salinity and plant life (the algae). Moreover, it has closed a large number of internal springs of the Lake, reduced the volume of the reservoir, prevented the natural circulation of water and of materials dissolved in the water, and increased the sedimentation rate (which has turned the relatively deep part of the lake into a relatively flat bed) (DOE, 2013c). 
Fig5. Changes in Cultivation

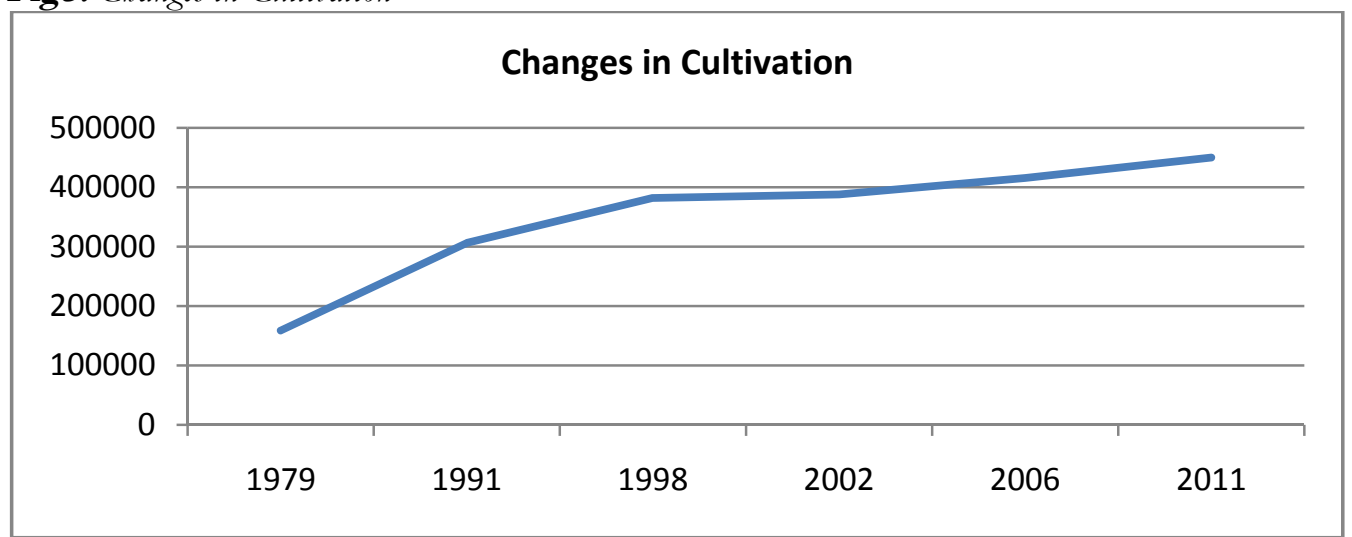

Source: Extracted from DOE $2013 \mathrm{~b}$.

Fig6. Images of The Shahid Kalantari Highway

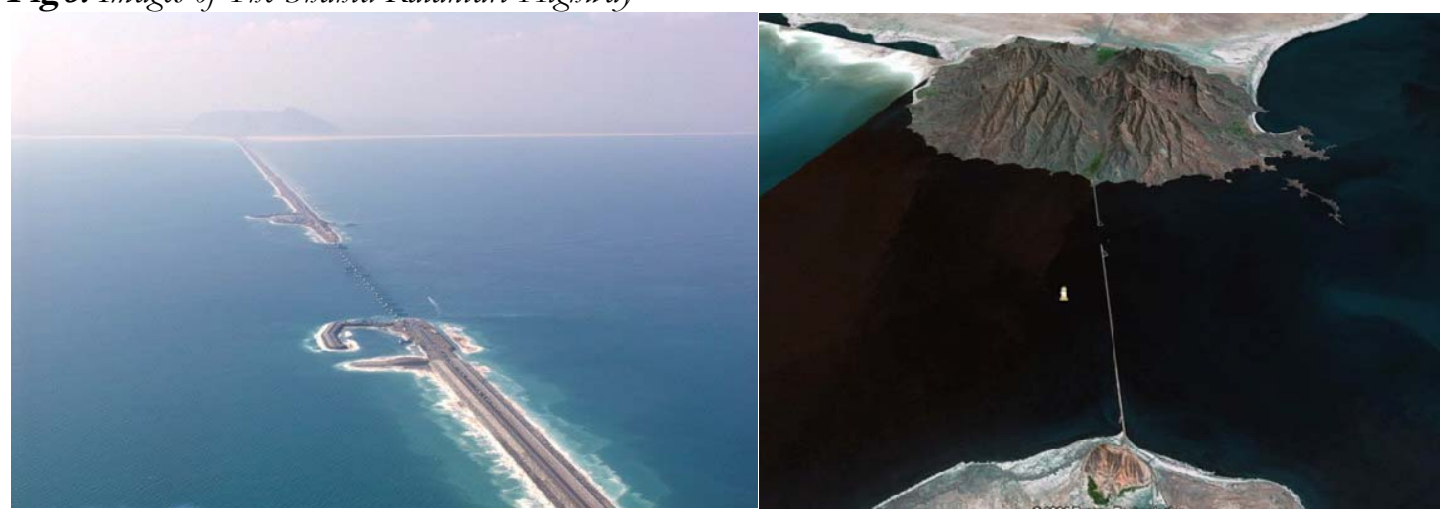

Source: DOE, $2013 b$.

\section{4-B- Consequences resulting from implementation of Development Plans in the Urmia Lake Environment}

\section{i. Disruption of the biodiversity in the region}

The drying of Urmia Lake has led to the loss of sweet water wetland habitats south of the Lake; habitats that play a key role in supporting native and migratory wild life in the Lake. The serious disruption in the migration cycle of migratory birds (which has changed the natural, and one of the most important, flight corridors of migratory birds in the world) is another consequence. So is the destruction of the only living organism in the salty water of Urmia Lake (i.e., Artemia) that, besides having unique economic values, is the main food for migratory birds (DOE, 2013a).

ii. Increased salinity

Salinity has sharply increased in Urmia Lake in past years and reached 400 grams per liter (supersaturated salt water) from 160 grams per liter in high water years resulting in the appearance of salt crystals in the supersaturated salt water (DOE, 2012). 


\section{iii. Soil erosion}

Close to 50 percent of the Basin area (i.e., about 2.5 million hectares) is subjected to severe erosion, and erosion intensity (and sedimentation) in the whole Basin has been classified from moderate to high (DOE, 2013a).

iv. Pollution of water sources

Excessive utilization of groundwater sources has led to saline intrusion into the underground aquifers and not only does this threaten the continuation of activities in large parts of farmlands but it has also turned into a serious threat fort the quality of groundwater sources (Iranian Community Consulting Engineers, 2011). Intensification of farming activities in the Basin has resulted in increased consumption of agricultural chemicals. It is estimated that a million liters of pesticides and about 92000 tons of fertilizers are used in the regions around the Lake every year (Yekom Consulting Engineers, 2002). In general, about six million cubic meters of industrial wastewater, 138.4 million cubic meters of wastewater containing excess fertilizers and pesticides, and an unknown quantity of domestic wastewater are discharged in the Urmia Lake Basin every year (DOE, 2013a).

v. Salt dust

When the salt marshes of Urmia Lake expand, a mass of elements and various compounds will be dispersed in the air with every wind. This will lead to soil, crop, and orchard destruction (Iranian Community Consulting Engineers, 2011), cause respiratory diseases and eye diseases and problems, various kinds of cancer, and will seriously threaten the health of the society too.

vi. Weather changes in the region

Normally, the extensive area of Urmia Lake greatly helps to modify the microclimate (temperature and humidity) in the region and turn it into a suitable place for agriculture. Relative humidity also prevents the production and dispersion of dust in the region (DOE, 2010). The vast expanse of the Lake, and the feature of latent heat of evaporation resulting from it, has always had balancing effects on the micro (local) climate of the Urmia Lake basin. These effects mainly include increasing relative humidity in the dry season, reducing temperature during the warm season, and raising the temperature during the cold season. These effects, especially up to the altitude of 2000 meters where major population centers are located and agricultural and other activities take place, are observed more ((Iranian Community Consulting Engineers, 2011). Evidently, reduction in the area of the Lake will increase differences between the day and night temperatures and between seasons of the year, will reduce relative humidity, and will change the annual precipitation regime (Bagherzadeh Karimi, 2014).

\section{Conclusion}

Development with the economic growth approach changes the natural systems of the planet and leads to numerous environmental hazards that can threaten the economic and political systems of countries. Therefore, it is very possible for a political entity to attain development, but sustained development will be faced with serious doubts because environmental aspects are ignored.

Given the above- mentioned approach, this research studied the relationship between economic development and the environment, with Urmia Lake as a case example. The 
water level in Urmia Lake was at its highest in 1995. Since then, and up to 2011, we witnessed a sharp drop in the water level amounting to more than seven meters. Findings of the research show that implementation of Development Plans has been one of the main reasons for the drying up of the Lake. At present there are about 95 dams in the Urmia Lake Basin. Well, water utilization has increased very rapidly in the past two decades and has depleted more than 90 percent of the water in the aquifers. The agriculture sector is the most important consumer of the water in this Basin and has experienced remarkable changes during the last three decades. Another destructive factor of the Lake was the construction of a causeway the most part of which was built by constructing a levee in the Lake.

Consequences resulting from implementation of Development Plans in the Urmia Lake environment are mainly include disruption of the biodiversity in the region, increased salinity, soil erosion, pollution of water sources, salt dust, weather changes in the region that can threaten the sustainability of development. Then, sustainable development will be faced with serious doubts because environmental aspects are ignored.

\section{References:}

Bordessa, R. (1993). Geography, Postmodernism, and Environmental Concern”, The Canadian Geographer, 37, No 2.

Bagherzadeh Karimi, M. (2014). Environmental Challenges Due to Drying up of Urmia Lake. Department of Environment of Iran, Urmia Lake Restoration Staff.

DOE; Department of Environment of Iran (2010). Integrated Management Plan for Lake Urmia Basin. Prepared in Cooperation with Governmental Organizations, NGEOs, and Local Communities of Lake Urmia Basin.

DOE (2012). Report of Lake Urmia Conditions. Urmia Lake Restoration Staff.

DOE (2013c). Report of Geology Committee. Urmia Lake Restoration Staff.

DOE (2013a). Urmia Lake: Challenges, Actions, and the Way Forward. Urmia Lake Restoration Staff.

DOE (2013b). Report of Strategies to Save Urmia Lake. Urmia Lake Restoration Staff.

Escobar, A. (1995). Encountering Development: The Making and Unmaking of the Third World. Princeton University Press.

Etaat, J., et al., (2013). The Principles of Sustainable Development in Iran. Tehran: Elm Publication.

Heydari, N. (2013). Physical Chemistry of Urmia Lake. Department of Environment of Iran, Urmia Lake Restoration Staff.

Iranian Society of Consulting Engineers (2011). Sustainability Evaluation of Development Process and its consequences on Urmia Lake (Environmental Crisis in Urmia Lake).

Leftwich, A. (2006) States of Development: On the Primacy of Politics in Development. Translated to Persian by Javad Afshar Kohan, Mashhad, Merendiz Publications.

Potter, R.B. , Conway, D. (2011). In John Agnew and David N. Livingstone, The Sage Handbook of Geographical Knowledge. SAGE.

Sarrafi, M. (1998). The Principles Regional Development Planning. Tehran, Planning and Budget Organization, Center of Scientific and Economic Documents.

United Nations (1992). Agenda 21.

UNEP (2012), The Drying of Iran's Lake Urmia and its Environmental Consequences, Available on www.unep.org

Warf, B. (2006). Encyclopedia of Human Geography. SAGE Publications, Inc.

WCED (1987).Brundtland Report; United Nations World Commission on Environment and Development. United Nations.

West Azerbayijan Regional Water Authority Website: http:/ $/$ www.agrw.ir/index.php?option $=$ com content\&view $=$ article\&id $=33$ :lakestats\&catid $=2 \&$ Itemid $=50 \&$ lang $=$ fa

Yekom consulting engeeners (2002). Management Plan for the Lake Urmia Ecosystem. 4 Volumes. 